\title{
Abandoned mines - environmental, social and economic challenges
}

\author{
K Bennett MWH Australia Pty Ltd, Australia
}

\begin{abstract}
The environmental, social and economic problems associated with abandoned mine sites are serious and global. Abandoned mines may pose unique and complex challenges, often leaving negative impacts such as: safety and health hazards for people and animals, neglected mining heritage and other assets, in addition to economically-depressed communities.

Acid and metalliferous drainage (AMD), also known as acid mine drainage, is one of the negative environmental impacts on water quality that can result in a subsequent loss of biodiversity. AMD impacts can occur from underground workings, open pit mine faces, waste rock landforms, and tailings storage areas that were left exposed to the elements or inadequately rehabilitated, resulting in the contamination of water with dissolved metals and acidity.

Social and economic impacts on countries and individual communities can be due to issues such as: a loss of the productive land, loss or degradation of groundwater, pollution of surface water by sediments or salts, changes in river regimes, air pollution from dust or toxic gases or risk of falls into shafts or open pits.

Resources for cleaning up abandoned mines are very limited in most jurisdictions. A strong policy framework is required and, in order to be effective, primary policy elements must be embedded in the legislative framework. This paper explores the international dialogue that has taken place on abandoned mines, our improved understanding of legal liability, funding remediation and rehabilitation and the strategies that are in place to minimise the likelihood of more mines being abandoned.
\end{abstract}

\section{Introduction}

The historic mining of hard rock minerals such as gold, lead, copper and silver was a powerful incentive for exploration and settlement of the Australian mineral fields and American West. Mineral development often provided the economic base on which many remote communities were established. When orebodies were mined out and miners left to find other new deposits, they often left behind a legacy of abandoned mines, associated safety hazards, and contaminated land and water (BLM 2007). In the absence of applicable legislation, historic mining companies were not obligated to rehabilitate mines or set aside funds for rehabilitation.

The scale, intensity, risks and impacts of mining have changed significantly since mining first started. While not universal to all commodities or situations, this has been influenced by declining ore grades, a transition/expansion from underground to open cut mining, an increase in mine waste and extent of disturbed area, increasing waste rock to ore ratios, an increase in dewatering related to deeper mines, and often an associated increase in resource and energy intensity (Mudd 2009).

Standards have changed and some practices that were acceptable in the past are not today. The potential for creating new mining legacies is reduced in areas where mining-related legislation is in place for mine closure, and financial assurance is provided for the proposed rehabilitation activities before a new mining project is approved.

Contemporary mining companies must balance a range of factors including optimisation of capital and operating costs, risk management, stakeholder expectations, changes to operational viability, life-of-mine costs and regulatory requirements. These often competing factors have the potential to significantly 
influence the operation of a mine and, if not managed appropriately, could translate into an increase in impact and liability, premature closure, and a future mining legacy. Mining legacies reflect poorly on an industry which is under increasing scrutiny and the focus of raised community expectations for mine closure outcomes (Pepper et al. 2014).

Abandoned mines are used as examples of the failure of the regulatory process to protect the environment and communities. Their existence undermines trust in both governance and the industry and can result in the withdrawal of the social licence to operate (Unger et al. 2014).

The future of the mining industry is dependent on the legacy it leaves. Industry reputation is affected when mines are abandoned or long-term detrimental environmental impacts emerge because they were not appropriately addressed during the life of the mine. Industry today recognises that to gain access to future resources it needs to demonstrate that it can effectively manage and close mines with the support of the communities in which it operates. Hence, there is the need to continue to work together on a national and international scale to address the existing environmental, social and economic problems associated with abandoned mine sites and reduce, as far as practicable, the creation of new ones.

\subsection{Defining an abandoned mine or mining legacy}

A review of work done to date indicates that there is no single definition of 'abandoned mines', as they can also be called derelict, orphan, former or legacy mines. Abandoned mines are recognised as having incomplete rehabilitation, however, the question is, what constitutes an abandoned site - is it a single shaft or an entire mining area?

The United Nations Environment Programme (UNEP), 2000, outlines that a key problem associated with abandoned mines is that of ownership: some sites are owned by someone other than the state but the state may be responsible for any clean-up because of the financial state of the company or individual.

In 2001 UNEP described abandoned mine sites as: "one of the major outstanding international environmental problems related to mining. It is a legacy of centuries old practices and of inadequate, insufficient or non-existent mine closure. The potential costs of rehabilitation, the lack of clearly assigned (or assumed) responsibility, the absence of criteria and standards of rehabilitation and other factors have delayed action by all parties - industry, governments, and communities" (UNEP \& Cochilco 2001).

In Australia, the definition of an abandoned mine varies from state to state. The Queensland Government (2015) classifies a mine as abandoned or orphaned when "a mining tenure no longer exists and there are no legal avenues requiring the company, or individuals that created the mining disturbance, to carry out remediation." The term 'derelict mines' is applied in New South Wales, and the Northern Territory (NT) refers to 'legacy sites', whereas Victoria combines abandoned mines with other sources of contamination under 'contaminated land' programmes.

The Western Australia (WA) Mining Rehabilitation Fund Act 2012 (the MRF Act) and regulations are used to define an abandoned mine site. Within WA an abandoned site can be declared by the minister, and the regulations state that the Mining Rehabilitation Advisory Panel may advise the minister on the identification of land that is suitable to be declared to be an abandoned mine site. At the time of writing this paper, the Government of WA Department of Mines and Petroleum, (DMP) draft Abandoned Mines Policy, defined abandoned mine sites as: "areas of land impacted by former mining activities for which no individual, company or organisation can be held responsible for rehabilitation. An abandoned mine site may comprise of multiple areas of land or site features (e.g. mine shafts, waste dumps, abandoned equipment) that may or may not be adjacent to each other" (DMP 2015).

The Strategic Framework for Managing Abandoned Mines (MCMPR \& MCA 2010) defines abandoned mines as: “... mines where mining leases or titles no-longer exist, and responsibility for rehabilitation cannot be allocated to any individual, company or organisation responsible for the original mining activities." (p 6). 
The AusIMM's 2013 Abandoned Mines Policy Statement describes abandoned and orphan sites as sites that: "... require rehabilitation and/or management but the owner of the site is either unable to be located or is unable or unwilling to undertake the required rehabilitation and/or management of the site." ( $p 1)$.

Pepper et al. (2012), noted that "while it can be important to distinguish between abandoned and orphan mines in terms of responsibility, liability, solutions and management response; to focus only on abandoned mines is to ignore the problem that exists in existing leases and titles."

The Canadian National Orphan/Abandoned Mines Initiative (NOAMI) (2015) definition integrates both abandoned mines and mines where a problem can exist under a current lease or title. "Orphaned or abandoned mines are those mines for which the owner cannot be found or for which the owner is financially unable or unwilling to carry out clean-up."

The United States of America (USA) Abandoned Mine Land (AML) (2015) program, managed by the Bureau of Land Management defines: "Abandoned mine lands are those lands, waters, and surrounding watersheds contaminated or scarred by the extraction, beneficiation or processing of coal, ores and minerals. Abandoned mine lands include areas where mining or processing activity is determined to have ceased."

Unger (2010) describes abandoned mines as those that: “...have no company managing those impacts after the minerals have been extracted and governments either accept, or inherit by default, these liabilities. Pepper et al. (2012) uses mining legacies as an umbrella term which encompasses abandoned, orphan and derelict mine sites, building on previous work by Whitbread-Abrutat (2008) and Worrall et al. (2009).

Whitbread-Abrutat's (2008) definition of a negative mining legacy is "...the impacts of a closed mine that continue to negatively affect the environment or associated communities" ( $\mathrm{p} 3)$. He then further divided this into (1) abandoned sites "where the owner is known, but for some reason, is unable or unwilling to take the necessary remedial action" and (2) orphaned sites "where the legal owner cannot be traced" ( $\mathrm{p} 3$ ).

Worrall et al. (2009) defined legacy mined land as "...land which has been mined and is now being used for another purpose, or is orphaned, abandoned or derelict and in need of remedial work" ( $p$ 1429).

Pepper et al. (2012) recommends that defining the issue using the term "mining legacies, encompassing all sites requiring management or rehabilitation, allows a more complete and comprehensive discussion of the problem, providing for appropriate solutions, rather than limiting the focus".

\section{International and Australian regulatory frameworks}

Resources for cleaning up abandoned mines are very limited in most jurisdictions. A strong policy framework is required and, in order to be effective, primary policy elements must be embedded in the legislative framework.

Collaborative national and international plans and guiding bodies enable key obstacles relating to regulation and management of legacy sites to be appropriately addressed. In the absence of national guidance and leadership, the environmental, social and economic challenges have the potential to be insurmountable.

\section{$2.1 \quad$ USA}

The USA AML (2015) Portal states its purpose is to provide "one voice" messaging from U.S. Federal environmental and land management agencies related to the environmental, health, and safety impacts of AMLs. It serves as an information repository about the different types of AML sites and their associated environmental, health, and safety issues and also highlights Federal, state, local, and tribal resources and success in AML reclamation activity.

The AML (2015) Web Portal was created by the Federal Mining Dialogue (FMD), a national level forum of Federal agencies working together and committed to enhancing the collaboration, coordination and partnership needed to address the complex issues surrounding the nation's AML sites. The FMD is focused 
on bringing together Federal agencies to identify and discuss technical and policy issues associated with the identification, clean-up, and reuse of AML sites across the country.

AMLs exist across private, mixed, and Federal lands adding to the complexity of the issue. A number of Federal statutes address environmental contamination issues associated with AMLs. Federal statutory authority is spread among several agencies with no one agency having overall statutory responsibility. Ensuring that appropriate authorities are used at AML sites will work to facilitate clean-up (AML 2015).

\subsection{Canada}

Canada initiated the mine environment neutral drainage (MEND) program in 1989. This was the first international multi-stakeholder initiative to develop scientifically-based technologies to reduce the effect of acidic drainage. The original program and its subsequent initiatives have contributed enormously to the understanding of acidic drainage and how to prevent it. MEND focused the acidic drainage effort and developed a toolbox of technologies that is available to all stakeholders. NOAMI subsequently adopted the MEND framework to develop a policy-based program for remediation of orphaned and abandoned mine sites in Canada (Tremblay et al. 2012).

The NOAMI (2015) website outlines the history of NOAMI which commenced in 1999 and 2000 when a number of stakeholders put forth requests to the Mines Ministers in Canada to establish a joint industry-government working group, assisted by other stakeholders, to review the issue of abandoned mines. The ministers supported this initiative and requested that a multi-stakeholder workshop be organised to identify key issues and priorities. Participants developed consensus on objectives and guiding principles for further work and recommended that a multi-stakeholder National Orphaned/Abandoned Mines Advisory Committee be formed to study various issues and initiatives relating to the development of partnerships in the implementation of remediation programs across Canada.

Workshop recommendations were presented at the Mines Ministers' Conference held in September 2001 at which Ministers agreed on the importance of a large-scale program for the rehabilitation of orphaned/abandoned mine sites and endorsed the recommendation to form a National Advisory Committee. The guiding principles and objectives from the 2001 workshop underpin the terms of reference for activities of the National Advisory Committee throughout its duration (Castrilli 2007).

This lead ultimately to NOAMI, a multi-stakeholder group and hub formed to facilitate a planned and coordinated response to mining legacies. Today, NOAMI provides support across Federal and provincial jurisdictions through an advisory panel of industry, government and community representatives. While NOAMI has achieved progress at some of the worst sites, including Giant Mine and Britannica, a lack of funds commensurate with the task means progress is slow. Pepper et al. (2014) identifies NOAMI as a good example, of the leadership and coordination that has been called for in Australia since 2003 but which still does not exist. Collaboration between industry, government and other stakeholders is a key component of the NOAMI model.

A review of NOAMI between 2002 and 2007 by Castrilli (2007) noted that a central theme of numerous recommendations at this time identified that: "...the orphaned/abandoned mine problem must be addressed directly and comprehensively in legislation and that such legislation should include a permanent funding approach (primarily a dedicated orphaned/abandoned mine fund) toward this purpose."

NOAMI is a co-operative Canadian program guided by an advisory committee and composed of the mining industry, Federal, provincial and territorial governments, environmental non-government organisations, and First Nations. The advisory committee created several task groups to address different aspects of the orphaned/abandoned mine problem. The task groups notably focus on: information gathering, community involvement, legal and regulatory barriers to voluntary collaboration in undertaking clean-up measures, funding models and approaches, and guidelines for legislative review (Castrilli 2007).

UNEP (2000) noted that "contaminated sites programs have led to the development of national approaches to assessment, preparation of inventories, prioritisation, objective setting and developing action plans." And 
that "there are perhaps, lessons to learn from these programs, by applying some of the methodologies that have evolved in a new context to orphan mine sites." In 2014 Unger et al. noted that the accessibility of web-based information on the British Columbia Crown Contaminated Sites Program (CCSP) was enhanced by the availability of biennial performance reports; in comparison it was difficult to find performance reports on abandoned mine programmes in Australia. Stewart (2015) noted that of particular relevance to mine closure is that the CCSP has demonstrated leadership in using a risk-based approach to assess and prioritise sites and protect human and ecological health.

\subsection{Australia}

In Australia, despite a non-legally binding national policy, there is currently no national government agency with statutory responsibility for remediating abandoned mines. With a few exceptions, each state or territory is independently responsible for abandoned mines on Crown land and private landholders are responsible for abandoned mines on freehold land, although there are some abandoned mines that are the responsibility of the Australian Government.

An Abandoned Mine Workshop (Bell 2003) recommended Australia develop a national strategy for managing abandoned mines and in December 2010 a 'Strategic Framework for managing Abandoned Mines in the Minerals Industry' (MCMPR \& MCA 2010) was finalised. The MCMPR consisted of the Australian and New Zealand Government Ministers for Resources, Energy and Tourism, and state and territory ministers with responsibility for minerals and petroleum. MCMPR no longer exists and its functions were devolved to the Standing Council on Energy and Resources (SCER). SCER is a council established by the Council of Australian Governments (COAG) to pursue priority issues of national significance in the energy and resources sectors, and progress the key reform elements facing the mineral, petroleum and energy sectors.

At a national level, the Strategic Framework (MCMPR \& MCA 2010) was prepared to encourage convergence of state and territory jurisdictions on the following aspects:

- Site inventories and data management.

- Improved understanding of liability and risk relating to abandoned mines.

- Improvement in performance reporting.

- Standardisation of processes and methodologies.

- Knowledge and skills sharing across jurisdictions.

Three jurisdictions (Queensland, New South Wales and Tasmania) had formal abandoned mine programmes prior to the completion of the 2010 Strategic Framework. Since 2010, WA and the NT have introduced new policies to address mining legacies. Unger et al. (2014) noted that "very few jurisdictions have up-to-date inventories that are publicly accessible and nor do they have a transparent process to assess risks and prioritise sites at a jurisdiction-wide level. Performance reports on completed jurisdictional programs are hard to find. However, it is possible to find reports on specific abandoned mine sites and rehabilitation projects in some jurisdictions."

The WA Draft DMP (2015) policy was developed to establish the principles that should be used in making decisions about the management and/or rehabilitation of these sites. "Management decisions regarding abandoned mine sites need to balance risk, costs and benefits to both the environment and the Western Australian community, and also recognise the varying values of abandoned mines."

Unger et al. (2012) recommends that "in order to understand the cumulative environmental and socio-economic impacts and potential opportunities of abandoned mines in Australia, there is a need to have spatially-accurate data across jurisdictional boundaries which describes many facets but in particular, the area of disturbance, commodity type and the mine features present (e.g. pits, waste dumps, shafts, tailings storage facilities)." ... "The goal is for Australian programs to progressively move towards mature programs 
consistent with international benchmarks for leading practice in other developed countries and thus, over time, to greatly reduce national liabilities."

\subsection{Legal liability}

A fundamental problem associated with the thousands of abandoned mines is the issue of legal liability for funding remediation and rehabilitation. Applying environmental management tools requires skills, technologies and financial inputs. Rehabilitation is characteristically a lengthy and costly process and apportioning responsibility for rehabilitation of historical mines is often complex, and liability can fall back on the state or the community. Pepper et al. (2014) recommends full liability accounting to understand the scale of the issue and the associated risks, so that funding issues and opportunities can be explored.

Unger et al. (2014) noted that "few websites recorded the total liability of abandoned mines. It is not clear whether this liability was known or unknown but it was rarely if ever available via the websearch of mines' departments who are the primary agencies to have responsible for mining legacies in Australia. As a result, researchers and the public cannot easily assess how much of the total liability is being addressed each year."

THE USA Office of Surface Mining Reclamation and Enforcement (OSMRE) (2015) outlines that funding for hard rock mines can come from the Environmental Protection Agency's (EPA) Superfund program, Clean Water Act grants, watershed programs run by the U.S. Forest Service and Bureau of Land Management, state sources and others.

The United States Environmental Protection Agency (EPA) (2015a) outlines the history of the Superfund which commenced in 1980 when congress passed the Comprehensive Environmental Response, Compensation, and Liability Act (CERCLA) to address the dangers of abandoned or uncontrolled hazardous waste dumps by developing a nationwide program for: an emergency response, information gathering and analysis, liability for responsible parties, and site clean-up. CERCLA also created a Trust Fund (or Superfund) to finance emergency responses and clean-ups. In 1989 the EPA initiated the Enforcement First policy where the EPA gives first priority to finding the parties who are potentially responsible for a release and gets them to address the problem they created.

The OSMRE (2015) website clarifies that no single agency is in charge. For example, current coal mine operators in the USA pay into the AML Reclamation Program which then distributes money to states to clean-up and rehabilitate abandoned coal mines. In the early years, the AML program focused on the physical reclamation of hazards affecting coalfield communities. More recently, the program began working to reclaim the vitality of communities left impoverished and degraded by past coal mining. Uranium mines, too, are treated separately - a select few get Superfund money, but most are handled by the Department of Energy.

In Australia both the WA and NT governments have introduced a levy based on the disturbance area. The WA Mining Rehabilitation Fund (MRF) became operational in 2013 and requires all Mining Act tenement holders to annually report on areas of disturbance on their tenements and, providing they meet a minimum threshold, pay a levy based on the disturbance area. The MRF funds are to be used to rehabilitate future abandoned mine sites, when all other avenues to ensure rehabilitation have been exhausted. Interest generated from the MRF is to be used to rehabilitate legacy abandoned mine sites (sites located on tenements that have not had an MRF reporting obligation) (DMP 2015).

The NT Government (2015) website describes the changes made in 2013 to the NT Mining Management Act 2013 (MMA), to enhance operation of the Act and strengthen environmental regulation. A key component of this was the introduction of an annual levy on mining securities. The NT Department of Mines and Energy (DME) still holds a minimum 100\% security for each site which has been in place since 2005.

\section{The extent of the problem}

The reality is that it is neither practical nor desirable to rehabilitate all abandoned mine sites. Old abandoned mines can be interesting due to their heritage and instructive in terms of providing examples of 
environmental impact when appropriate controls have not been implemented. The question is what constitutes an environmental concern - many adits discharge a trickle of acid and metalliferous drainage (AMD) but is it worth doing anything about it?

We know that knowledge in the techniques of rehabilitating both operational and abandoned sites is extensive and that there are many types of mines, each with their own unique characteristics, making clean-up efforts varied, both in terms of cost and approach. Pepper et al. (2014) states that a lack of data and different state based approaches complicates attempts to quantify mining legacies as a national issue. Tremblay et al. (2012) recommended that "what is needed is a set of 'common parameters' and qualifiers for designing and constructing a suitable database on abandoned mineral sites. General parameters could include basic information such as type of mine, location etc., while more specific parameters might include specific hazards and risks at each particular site to assist in establishing a data management system which quantifies the extent and complexity of the problem."

The United States EPA (2015a) separates abandoned mines into three main categories, namely: coal, hard rock, and uranium. This agency clearly recognises that it has "no system for monitoring the hundreds of thousands of abandoned mines across the American landscape, or knowing which one could be the source of the next big toxic spill. Old mines are forgotten, unless someone sounds the alarm."

Different regions and states in Australia have commenced populating datasets that detail the location and potential hazards associated with abandoned mine sites. Australia has more than 50,000 mining legacy sites, though more accurate and probably higher figures have been restricted by unclear definitions, different classification systems and lack of data (Unger et al. 2012).

Unger et al. (2014) identifies that in some jurisdictions in Australia there is little or no information on abandoned mine programmes or individual abandoned minesites on government websites, while other jurisdictions provided very detailed programme information on planning, funding and implementation. Those which have a detailed and current inventory of jurisdiction-wide abandoned mines are recognised as being more mature than those which lack this foundational knowledge.

The Queensland Government (2015) website states that there are currently over 15,000 identified abandoned mine sites across Queensland, with an estimated 3,500 of those on state-owned land. Of these, most are very small. However, there are about several hundred medium to large sites where significant mineral processing and smelting was carried out. The largest abandoned mine site is the former Mount (Mt) Morgan Gold Mine, located $32 \mathrm{~km}$ southwest of Rockhampton in Central Queensland.

In WA, where mining has occurred for more than 150 years, there are many thousands of workings that were abandoned after exploration or mining. Few of these site workings and their associated features have been recorded, with the majority remaining undocumented. As a result, the health, safety or environmental risks and potential historical, cultural, social, environmental, educational or economic value of these sites are unknown. In 1997, the then Department of Minerals and Energy commenced a programme to capture, from a safety perspective, baseline data relating to historical mining-related features. While not a complete record of the abandoned sites in the state, the WABMINES database currently contains over 190,000 abandoned mine site features (DMP 2015).

A key component of the DMP draft Abandoned Mines Policy is the risk assessment principle, whereby:

"1. A risk-based approach focussed on community safety and environmental impact should be taken to prioritise sites for active management and/or rehabilitation.

2. Risks associated with site opportunities should be identified and analysed to inform the management and/or rehabilitation solution decision" (DMP 2015).

Unger et al. (2014) notes that risk assessment and prioritisation processes are difficult to find in the public domain. However, legislation and policies which guide and support the risk evaluation and management process can prevent negative legacy creation and manage existing legacies. 
Abandoned mine challenges and opportunities are of a multi-disciplinary nature. Environmental, safety, stability and potential health impacts must be evaluated and managed. Post-mining values must also be understood if socio-economic development can be derived from these sites, in the form of further mineral extraction, heritage conservation and tourism, skills development through training and education and employment and alternative innovative uses (Pearman 2009; Unger 2009).

\section{$4 \quad$ Environmental challenges}

UNEP (2000) and Sphiwe (2015) recognise that the common physical and environmental problems characterising most abandoned mine sites include: altered landscape, open pits and shafts, land no longer usable due to loss of soil, pH levels, areas of steep slopes, abandoned mine waste disposal facilities, changes in ground and surface water regimes, contaminated soils and aquatic sediments, subsidence, changes in vegetation cover, derelict sites with compacted soil, and burning coal waste dumps and workings.

Water resources are frequently polluted by abandoned mines as they are conduits through which contaminants escape to the environs away from the immediate mine sites. The chemistry of the discharge from mines varies greatly as does the effect, the drainage from a mine may be alkaline, moderately or highly saline, alkaline and ferruginous or acidic and ferruginous. The potential treatment is challenging as the alteration in the quality of the water can be due to reactions occurring across a large diffuse area that may cover tens of square kilometres.

Johnston et al. (2008) states that the treatment of mine water discharge is well understood in Britain due to the legacy of mining coal, metal ores and other minerals since the Bronze Age, and the mining of lead and copper on an industrial scale since the Roman occupation. Many thousands of abandoned mines now discharge mine water containing metals (such as cadmium, iron, copper and zinc) and other pollutants into adjacent watercourses. Metal mines in the ore fields of Wales, the southwest and northern England continue to cause pollution despite being closed for over a hundred years.

On an international scale, it is evident that one of the most serious environmental concerns from abandoned mines is AMD, which is generated from underground workings, open pit mine faces, waste rock piles, and tailings storage areas that were left exposed to the elements or inadequately rehabilitated, resulting in the contamination of water with dissolved metals and acidity. The resultant environmental impact on downstream aquatic ecosystems and water users is often extensive.

AMD can form when sulphide minerals, mostly pyrite (iron sulphide and its close mineralogical cousins), are exposed to water and oxygen in the surface environment, causing sulphide oxidation and the formation of sulphuric acid, which in turn leaches salts and heavy metals (including radionuclides). If AMD enters a stream, the metals concentrations can be hundreds or thousands times higher than the levels which can kill most biodiversity, effectively wiping out the ecology of that stream. As the AMD flows downstream, it will be diluted along with chemical reactions removing some or most of the metals (especially as the acid is removed), and so at some point there will be a return to a normal ecosystem. The distance a stream can be impacted varies depending on the size of the AMD source, hydrological characteristics (especially rainfall and flow frequency), the geochemical nature of the mine wastes and geology of the catchment, among other factors (Mudd 2013).

Australian examples of ongoing AMD impacts include, but are not limited to, Rum Jungle (NT), Mt Lyell (Tasmania) and the Mt Morgan Mine (Queensland). Mining commenced at Mt Morgan in 1882 and continued to operate until 1981. Over its lifespan, the mine yielded approximately 250 tonnes of gold, 37 tonnes of silver and 360,000 tonnes of copper; approximately 134 million tonnes of waste rock and tailings were generated. An acidic environment was utilised to extract the copper, consequently the tailings have an average $\mathrm{pH}$ of 2 (highly acidic). Mudd (2013) reports that the mine was never rehabilitated, hence the mining activities have left a legacy of impacts on the Dee River and the site itself. Once mining in the open cut stopped, AMD-rich waters began to fill the open pit (Figure 1). Water in the pit contains elevated levels of copper, aluminium, magnesium and other metals. Regional flooding in January 2013 caused the pit to overflow for the first time, spilling acidic water into the river. The impacts of this pollution stretched for $50 \mathrm{~km}$. 


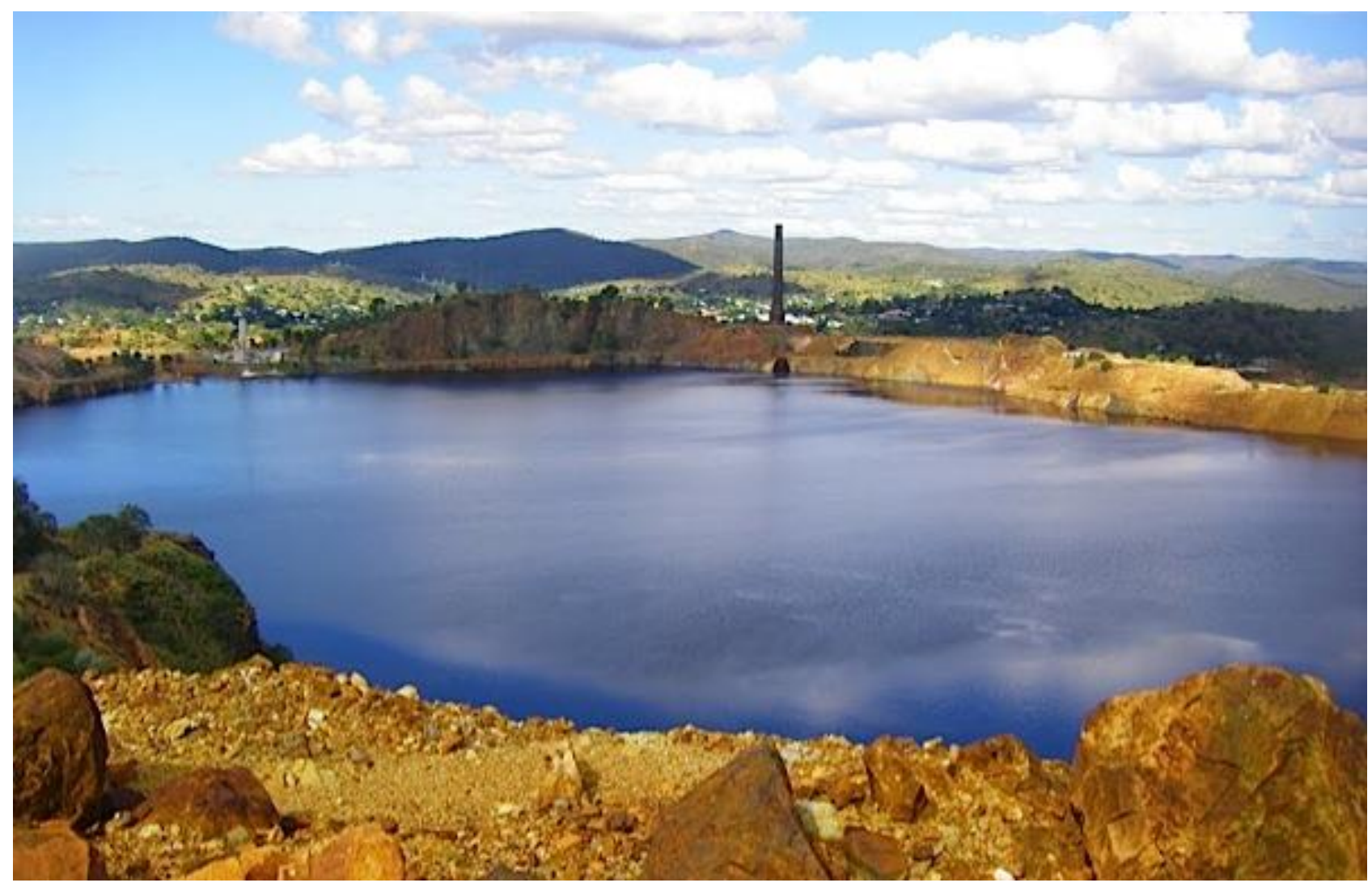

Figure 1 Mount Morgan gold, silver and copper mine, which is now filled with contaminated water (image courtesy of State Library of Queensland)

\section{$5 \quad$ Social and economic challenges}

According to Johnston et al. (2008), iron-rich water from the mines might have an aesthetic impact on the receiving water bodies, thus making the place less attractive for investment. This also makes the water unsuitable for other uses and, as a result, reduces the social and economic value of the water to the surrounding community.

Other socio-economic issues that arise from the environmental problems of inactive or poorly rehabilitated mines are loss of productive land, degradation of water resources which in turn have detrimental effects to aquatic life, change in river regimes, air pollution from dust and toxic gases, risk of injury or death as a result of falling into open shafts and pits, and risks of landslides (UNEP \& Cochilco 2001). In addition, dust and soils from abandoned mines might contain contaminants (silica, asbestos fibres, chromium and heavy metals) that are hazardous to health.

The Queensland Government (2015) website summarises the key risks to public safety and health from abandoned mine sites as:

- Unrestricted access to open mine shafts (Figure 2).

- Subsidence within community areas of historic mine shafts.

- Subsidence from underground mining areas.

- Pollution from residual mineralised stockpiles on mine sites, e.g. acid mine drainage. 


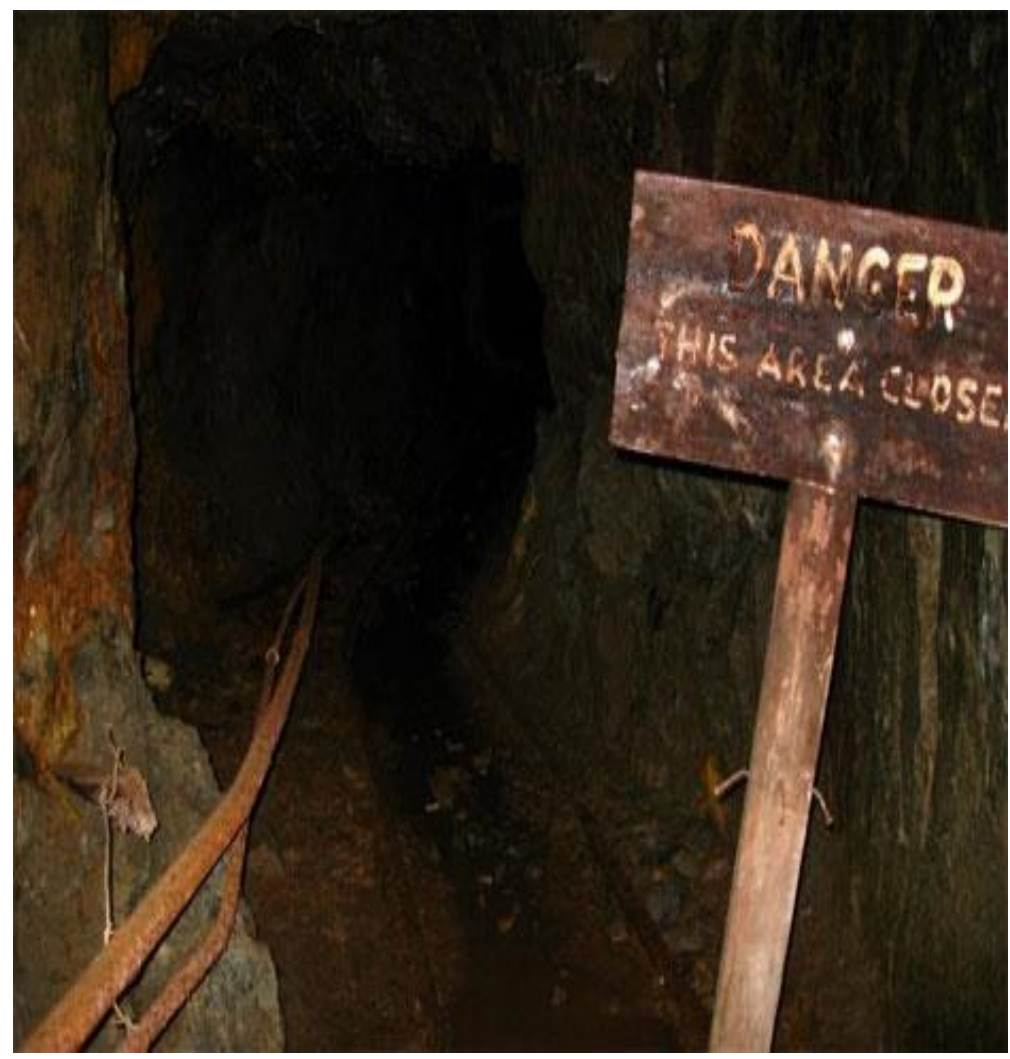

Figure 2 Unrestricted access to open mine shafts presents a public safety hazard

Public health and safety hazards at abandoned mine sites can also abandoned infrastructure and ground surface instability.

The social impacts of abandoned mines can have a profound effect on communities unable to diversify, consequently, sustainability, innovation and consideration of the unique assets and community values for each abandoned mine site are encouraged (MCMPR \& MCA 2010). This could include post-mining land uses such as mining heritage tourism, recreational uses or alternative businesses, when rehabilitation options for an abandoned mine site are investigated. Regardless of proposed future use, stakeholder consultation is a fundamental part of identifying values and developing appropriate (and acceptable) management options.

When assessing rehabilitation of an abandoned mine it is important to view mines not just as a liability and burden but as a potential asset (Unger 2012). The AusIMM (2013) report states "integrating mining heritage tourism with rehabilitation also provides an opportunity for interpretation of historic mining activities and socio-economic benefits to the community at large". However, community involvement is integral to the success, as is the requirement for a funding source to convert an abandoned mine into an asset.

\subsection{The Eden Project - Post-Mining Alliance, Cornwall, England}

The Eden Project in Cornwall, England is a charity and tourist attraction focussed on education and sustainable development. Established within a reclaimed kaolinite pit, the Eden Project is an excellent example of successful rehabilitation of an abandoned mine site. In addition to the attraction, the Post-Mining Alliance was formed to communicate what has been learned from this project and other leading practice projects globally where socio-economic regeneration has been particularly successful. Pearman (2009) observed that the key ingredients to successful regeneration projects include: "the development of local solutions to fit local circumstances; leadership, vision and commitment; creative partnerships for funding, development and implementation, collaboration with 'unusual suspects'. These partnerships involved developing shared interests, and community involvement and consultation at all stages to aid in developing shared responsibility and ownership. Finally, the uniqueness of the spectacle, along with good design were also key to success." 
Other factors identified by Pearman (2009) as potentially being of location-specific relevance that contributed to the success of projects included: "hybrid projects and multi-purpose sites; good location linked to transport; close to sizable population if visitor-dependent; links between heritage attractions in same region; government commitment to fund; and legislation (e.g. where biodiversity is a priority)."

\section{Policy and action}

Mining companies, governments and consultants have acquired a great deal more capability to deal with environmental and societal issues associated with mining impacts, such as water contamination from mine wastes, including acid generation. Through these efforts a significant advancement in environmental management has been achieved which has contributed to enhancing the long-term sustainability of the mining industry and its impact upon the environment (Tremblay et al. 2012).

However, it is imperative that any clean-up work proposed on an abandoned mine is approached with rigour. In August 2015, the US EPA's efforts to clean-up an abandoned mine near Silverton, Colorado, backfired. Workers were excavating an area above an old adit when pressurised water began leaking above the mine tunnel, sending 11.35 million litres of mining wastewater into the Animas River. The river turned mustard yellow as it carried the contaminants south through Colorado, Utah, and New Mexico (EPA 2015b).

Current best practices in mine closure requires the rehabilitation of decommissioned mine sites which incorporates returning the land, groundwater and surface waterways to agreed criteria. These practices can be applied to abandoned mines to generate positive outcomes in terms of both financial and corporate social responsibility.

Policies can be utilised to establish an acceptable level to which abandoned mines shall be rehabilitated, especially with respect to the requirement for stakeholder consultation and development of closure objectives and completion criteria. However, the cost of rehabilitating abandoned mines is poorly understood. Without this knowledge it is unlikely that a Federal government will set aside dedicated funds, write policies and develop intergovernmental cost-sharing arrangements to address remediation at high priority sites or implement the necessary programmes.

Unger et al. (2012) recognises that "gaps in knowledge as well as inadequacies in policies and legislation must systematically be addressed for holistic programs to persist over time, especially when changes of government and shifts in the demand for Australia's mineral resources superimpose other priorities on the mining sector and governments. Inter-generational equity requires a long term vision and persistent effort to address the negative legacies from mining, not only in Australia but also globally."

\section{References}

AML (Abandoned Mine Lands) 2015, USA Abandoned Mine Lands portal, viewed 18 August 2015, http://www.abandonedmines.gov/ ep.html/

AusIMM (Australasian Institute of Mining and Metallurgy, The) 2013, Abandoned Mines Policy Statement, June 2013.

Bell, LC 2003, Proceedings of the Workshop on management and remediation of abandoned mines, (ACMER) Australian Centre for Mine Environmental Research in association with the Minerals Council of Australia, Brisbane.

BLM (Bureau of Land Management) 2007, Abandoned Mine Lands: A Decade of Progress Reclaiming Hardrock Mines, Forest Service Publication (FS-891), September 2007.

Castrilli, J 2007, Wanted: A Legal Regime to Clean Up Orphaned/Abandoned Mines in Canada.

DMP (Department of Mines and Petroleum) 2015, Abandoned Mines Policy, Government of Western Australia, Draft for Consultation, July 2015.

EPA (The United States Environment Protection Authority) 2015a, viewed 15 August 2015, http://www2.epa.gov/superfund/superfund-history/

EPA (The United States Environment Protection Authority) (2015b), viewed 15 August 2015, http://www.epa.gov/goldkingmine

Johnston, D, Potter, H, Jones, C, Rolley, S, Watson, I \& Pritchard, J 2008, Abandoned mines and the Water Environment: Science project SC030136-41, Environment Agency, the Scottish Environment Protection Agency (SEPA), the Coal Authority (The Environment Agency et al.), Rio House, Waterside Drive, Aztec West, Almondsbury, Bristol.

MCMPR \& MCA (Minerals Council on Mineral and Petroleum Resources and Minerals Council of Australia) 2010, Strategic Framework for Managing Abandoned Mines. 
Mudd, GM 2009, The Sustainability of Mining in Australia: Key Production Trends and Their Environmental Implications for the Future, Department of Civil Engineering, Monash University and Mineral Policy Institute, Melbourne, VIC, p. 277.

Mudd, GM 2013, 'Australia's Mining Legacies', in Arena Magazine, (the Australian Magazine of Left Political, Social and Cultural Commentary).

NOAMI (National Orphaned/Abandoned Mines Initiative) 2015, viewed 15 August 2015, http://www.abandoned-mines.org/en/

NT (Northern Territory Government) 2015, viewed 19 of August 2015, http://www.nt.gov.au/d/ Minerals_Energy/?header=Legacy\%20Mines/

OSMRE (The USA Office of Surface Mining Reclamation and Enforcement) 2015, viewed 19 August 2015, http://www.osmre.gov/programs/aml.shtm/

Pearman, G 2009, 101 Things to do with a Hole in the Ground, Post Mining Alliance, Cornwell UK.

Pepper, M, Roche, C \& Mudd, G, 2012, 'Mining Legacies - Understanding Life-of-Mine Across Time and Space', in proceedings Life-of-Mine 2014 Conference, The Australian Institute of Mining and Metallurgy, Brisbane, p449-465.

Pepper, M, Roche, C \& Mudd, G 2014, 'Australia's mining legacy challenge', in proceedings Life-of-Mine 2014 Conference, The Australian Institute of Mining and Metallurgy, Brisbane.

Queensland Government 2015, viewed 15 August 2015, https://www.qld.gov.au/environment/land/abandoned-mines/

Sphiwe, EM \& Francis, AD 2015, 'A review of problems and solutions of abandoned mines in South Africa', International Journal of Mining, Reclamation and Environment.

Stewart, G 2015, 'British Columbia's Crown Contaminated Sites Program - a Ten Year Review', in AB Fourie \& M Tibbett (eds), Proceedings of the 10th International Conference on Mine Closure, InfoMine.

Tremblay, G \& Hogan, C 2012, Experience of Canadian Partnership Programs - Mine Environment Neutral Drainage and National Orphaned /Abandoned Mines Initiative, in Proceedings Life-of-Mine 2012, p11-12, Brisbane 10-12 July 2012, (The Australian Institute of Mining and Metallurgy, Melbourne) http://www.ausimm.cpm.au/lifeofmine2012/

UNEP (United Nations Environment Programme) 2000, Mining and Sustainable Development II - Challenges and Perspectives, Division of Technology, Industry and Economics, ISSN 0378-9993.

UNEP \& Cochilco (United Nations Environment Programme \& Chilean Copper Commission) 2001, Abandoned Mines - Problems, Issues and Policy Challenges for Decision Makers: Summary Workshop Report, UNEP \& Cochilco, Chile.

Unger, CJ 2009, Leading practice abandoned mine rehabilitation and post-mining land use, Churchill Fellowship report, p. 76, http://www.churchilltrust.com.au/media/fellows/UNGER_Corinne_2009.pdf

Unger, C, 2010, Science Alert, Abandoned Mine management, viewed 19 August 2015, http://www.sciencealert.com/abandonedmine-management-in-australia

Unger, C 2012, Value Proposition for National Abandoned/Legacy Mine Hub at CMLR/SMI/UQ, (Centre for Mined Land Rehabilitation (CMLR), Brisbane.

Unger, C, Lechner, A, Glenn, V, Edraki, M \& Mulligan, D 2012, 'Mapping and Prioritising Rehabilitation of Abandoned Mines in Australia', in Proceedings Life-of-Mine 2012, The Australian Institute of Mining and Metallurgy, Brisbane, pp. 259-266.

Unger, CJ, Lechner, AM, Walton, A, Glenn, V, Edraki, M \& Mulligan, DR 2014, 'Maturity of Jurisdictional Abandoned Mine Programs in Australia based on Web-Accessible Information', in Proceedings Life-of-Mine 2014, The Australian Institute of Mining and Metallurgy, Brisbane.

Whitbread-Abrutat, P 2008, Mining legacy survey, informing the background paper, Post-Mining Alliance, Eden Project, UK.

Worrall, R, Neil, D, Brereton, D \& Mulligan, DR 2009, 'Towards a sustainability criteria and indicators framework for legacy mine land', Journal of Cleaner Production, vol. 17, pp. 1426-1434. 